\title{
The comparison between therapeutic effects of different classes of antidepressant drugs in treatment of genetical and reactional depression
}

\author{
Parviz Molavi*, Karimollahi Mansoureh, M Faridi, H Mohammadnia, \\ P Dailami, R Arab and F Derakshani
}

Address: Ardabil Medical sciences University, Ardabil, Iran

* Corresponding author

from International Society on Brain and Behaviour: 3rd International Congress on Brain and Behaviour

Thessaloniki, Greece. 28 November - 2 December 2007

Published: 17 April 2008

Annals of General Psychiatry 2008, 7(SuppI I):S3 I5 doi:I0.I I86/I744-859X-7-SI-S3 I5

This abstract is available from: http://www.annals-general-psychiatry.com/content/7/SI/S3I5

(C) 2008 Molavi et al.; licensee BioMed Central Ltd.

\section{Background}

Depression as a common psychiatric disorder can occur in two types: endogenous or genetic and exogenous or reactional. These two types of depression, from the point of view of response speed to treatment and type of appropriate drug for treatment are different. This study has been executed to compare therapeutic effects of different classes of anti-depressant drugs in treatment of genetic and reactional depression.

\section{Materials and methods}

Present survey is a clinical-trial study, a completely randomly block type, that has performed on 30 patients (male and female). Selection of study sample accomplished randomly among unipolar depressed patients that has referred to Ardabil's psychiatry clinic diagnosed based on DSM-IV criteria. Researcher - Made questionnaire, Beck, and Catelle depression test were used to collect data. To analyze data, for completely randomly blocked designs, two-factor variance analysis method and $\mathrm{F}$ test were used.

\section{Results}

This study showed that genetical depression does not response treatment rapidly and its response type is not good and persistent. From the point of view of time, reactional depression has a delaying response but its response type is good and persistent. In addition, no difference was observed in efficacy of different classes of drugs for treat- ment of these two types of depression. The results of this research showed that there is no difference between treatment response of two types of depression (genetical and reactional).

\section{Conclusions}

There is no preference in efficacy of different classes of drugs in treatment of these two types of depression. 